\title{
Consumer acceptance and sensory evaluation of Monti Dauni Meridionali Caciocavallo cheese
}

\author{
A. Santillo, M. Caroprese, D. Ruggieri, R. Marino, A. Sevi, and M. Albenzio ${ }^{1}$ \\ Department of Production Sciences and Innovation in Mediterranean Agriculture and Food Systems (PrIME), University of Foggia, Via Napoli, 25, \\ 71100 Foggia, Italy
}

\begin{abstract}
Twelve Caciocavallo cheeses were collected from 6 factories (A, B, C, D, E, F) located in the Monti Dauni Meridionali area (Southern Italy) that adopted different protocols for cheese production. A total of 160 consumers were involved in the sensory evaluation of Caciocavallo cheese after $180 \mathrm{~d}$ of ripening. Cheese attributes were used to describe the flavor, texture, and appearance of cheeses. The highest scores for the shiny attribute were assigned to cheeses B, C, and E, whereas color intensity was the highest in cheeses B, D, and F. Strength, salty, and piquant attributes were higher in cheeses $\mathrm{F}$ and $\mathrm{A}$ because of the use of raw milk (F), rennet paste $(\mathrm{A})$, and percentage of salt in the brine $(\mathrm{A}, \mathrm{F})$. Consumers perceived a more granular structure during the second half of chewing of Caciocavallo cheese F, as evidenced by the highest value for the grainy attribute. A positive correlation was found between overall flavor and odor intensity and water-soluble nitrogen, low molecular weight peptides, and free fatty acids and between piquant and butyric and caproic acids. A principal components analysis applied to the sensory attributes accounted for $65 \%$ of the total variance. The score plot showed that cheeses F and A were located in a well-defined zone of the plot, with cheeses in this zone displaying higher levels of strength, piquant, and salty attributes. The preference test assigned $40 \%$ of the preference to Caciocavallo cheese A, $38 \%$ to cheese F, $9 \%$ to cheese E, $8 \%$ to cheese D, and $7 \%$ to cheeses B and C. Sensory evaluation of Monti Dauni Meridionali Caciocavallo cheeses is a useful analysis to highlight the principal attributes able to influence consumers' liking that are related to biochemical features of the cheese.
\end{abstract}

Key words: Caciocavallo cheese, sensory analysis, preference, consumer test

Received July 28, 2011.

Accepted April 11, 2012.

${ }^{1}$ Corresponding author: m.albenzio@unifg.it

\section{INTRODUCTION}

In recent years, consumers have had a growing interest in "typical" foods, defined as products made in a nonindustrial environment, either traditional or unique, and characterized by small-scale batch production with a limited degree of mechanization (Kupiec and Revell, 1998). Consumers' perceptions of typical food quality are strongly influenced by several factors, including personal preferences, cultural influences (Ophuis and Van Trijp, 1995), and perceived product authenticity (Kuznesof et al., 1997).

A wide variety of semihard pasta filata cheeses fall under the common name "Caciocavallo," including Russian, Balkanian, and Italian types (Piraino et al., 2005). In Italy, the general designation Caciocavallo is used for cheese made by using several protocols that differ in the milk used (raw or heat treated), the origin and typology of coagulant (animal or plant, liquid or paste rennet), and the starter culture (commercial, natural milk or whey cultures). The characteristic phases of Caciocavallo cheese production are acidification and stretching of the curd in hot water, resulting in a plasticized, homogeneous mass, which is afterward formed into cheese with no pressing, and finally salting in brine. Cheese may be sold after only 2 wk of ripening or, more commonly, after 2 to 4 mo or longer $(>12$ mo; Gobbetti et al., 2002). The features of Caciocavallo cheese depend on several factors, mainly represented by the coagulant, lactic acid microflora, and time of ripening, which significantly contribute to the texture, flavor, and aroma of the final cheese.

Caciocavallo cheese produced in the area of Monti Dauni Meridionali has been characterized by its microbial, chemical, proteolytic, and lipolytic features (Vernile et al., 2006; Albenzio et al., 2010), providing evidence of the important roles of milk quality and manufacturing techniques in the cheese-ripening process. In the present study, Monti Dauni Meridionali Caciocavallo cheese was evaluated by consumers for its sensory characteristics and consumer preference; results regarding flavor, appearance, and textural attributes of the cheese are presented and discussed. 
Table 1. Moisture, lower molecular weight peptides, total FFA, and salt in moisture at $180 \mathrm{~d}$ of ripening of Caciocavallo cheese produced by 6 factories located in the Monti Dauni Meridionali area

\begin{tabular}{|c|c|c|c|c|c|c|c|c|}
\hline \multirow[b]{2}{*}{ Variable } & \multicolumn{6}{|c|}{ Dairy factory } & \multirow[b]{2}{*}{ SEM } & \multirow[b]{2}{*}{ Factory effect } \\
\hline & $\mathrm{A}$ & B & $\mathrm{C}$ & $\mathrm{D}$ & $\mathrm{E}$ & $\mathrm{F}$ & & \\
\hline Moisture, \% & $35.5^{\mathrm{b}}$ & $38.85^{\mathrm{c}}$ & $38.82^{\mathrm{c}}$ & $34.75 \mathrm{~b}$ & $37.82^{\mathrm{c}}$ & $30.83^{\mathrm{a}}$ & 0.63 & $* * *$ \\
\hline $\mathrm{WSN} / \mathrm{TN},{ }^{2} \%$ & 72.01 & 81.92 & 70.38 & 66.11 & 83.52 & 73.07 & 7.63 & $* * *$ \\
\hline Total FFA, $\mu \mathrm{mol} / \mathrm{g}$ of cheese & $14.22^{\mathrm{d}}$ & $3.68^{\mathrm{a}}$ & $4.26^{\mathrm{b}}$ & $4.58^{\mathrm{b}}$ & $6.19^{\mathrm{c}}$ & $31.53^{\mathrm{e}}$ & 0.12 & $* * *$ \\
\hline Salt in moisture, $\%$ & $13.28^{\mathrm{bc}}$ & $8.57^{\mathrm{a}}$ & $12.31^{\mathrm{b}}$ & $11.02^{\mathrm{b}}$ & $15.29^{\mathrm{c}}$ & $13.65^{\mathrm{bc}}$ & 0.52 & $* *$ \\
\hline
\end{tabular}

${ }^{\mathrm{a}-\mathrm{e}}$ Means within a row with different superscripts differ $(P<0.05)$.

${ }^{1}$ Lower molecular weight peptides as a percentage of the $\mathrm{pH}$ 4.6-insoluble nitrogen fraction (reported in Albenzio et al., 2010).

${ }^{2} \mathrm{WSN} / \mathrm{TN}=$ water-soluble nitrogen/total nitrogen (reported in Albenzio et al., 2010).

${ }^{* *} P<0.01 ;{ }^{* * *} P<0.001$.

\section{MATERIALS AND METHODS}

\section{Cheese Samples}

Two cheese-making trials were performed in each of the 6 factories located in the Monti Dauni Meridionali area (southern Italy); 12 Caciocavallo cheeses were collected after $180 \mathrm{~d}$ of ripening. The production protocols of the 6 factories involved in the study and the principal indexes of cheese ripening at $180 \mathrm{~d}$ were detailed in a previous note by Albenzio et al. (2010). Table 1 summarizes the chemical parameters (moisture, lower molecular weight peptides, soluble nitrogen to total nitrogen, total FFA, and salt in moisture) of Caciocavallo cheeses at $180 \mathrm{~d}$, as determined in a previous note by Albenzio et al. (2010).

\section{Descriptive Sensory Analysis and Consumer Test}

A panel of 160 consumers, recruited from staff and students at the University of Foggia, was involved in the test; the panel members were equally distributed by sex and ranged in age from 20 to 50 yr old. The criterion for recruiting was cheese consumption at least once per week.

All panelists were familiar with basic sensory evaluation techniques, and before sensory evaluation, they participated in briefing sections to familiarize themselves with the specific vocabulary used to describe the cheese attributes. The descriptive vocabulary used to characterize the cheese flavor, appearance, and texture attributes is reported in Table 2.

Each sample was assigned a 3 -digit random number, and cheese slices $(1.5 \times 1.5 \times 1.5 \mathrm{~cm})$ from the 2 cheese makings of the same factory were randomly mixed so that all replications from the same batch were presented an equal number of times. A glass of water and unsalted crispy bread were also provided, and consum- ers were instructed to take a small bite of bread and a sip of water after each cheese tasting. For the sensory evaluation, panelists were instructed to evaluate their perception of the cheeses on a 10-point intensity scale, whereas for the acceptance rating test, panelists expressed their overall liking of the cheeses on a 10-point hedonic scale anchored with $0=$ dislike extremely and $10=$ like extremely, and with a neutral center point of neither like nor dislike.

The way the treatment combinations were divided between the sessions and the order in which the cheeses were presented were randomized to minimize any carryover effects (Muir and Hunter, 1992). At the end of the sessions, panelists were asked to indicate the preferred cheese among the ones tested.

\section{Statistical Analyses}

All the variables were tested for a normal distribution using the Shapiro-Wilk test (Shapiro and Wilk, 1965). Data were analyzed by ANOVA using the GLM procedure of SAS (SAS Institute, 2011), and the effect of dairy factory was tested on sensory attributes of Caciocavallo cheese. When significant effects were found (at $P<0.05$ ), Student's $t$-test was used to locate significant differences between means. Linear simple correlations were studied between sensory attributes and cheese-ripening indexes (soluble nitrogen at $\mathrm{pH}$ 4.6, percentage of low molecular weight peptides, FFA, and butyric and caproic acids, as previously published in Albenzio et al., 2010).

Principal components analysis was applied to a matrix of 10 sensory attributes (shiny, open, color, moisture, rubbery, grainy, fermented, strength, salty, and piquant) using the PRINCOMP procedure of SAS to study the main tendencies in variation between cheeses and panelist sex. The mostly significant 2 principal components were analyzed using a factorial analysis. 
Table 2. Descriptive vocabulary used to characterize flavor, appearance, and texture of Caciocavallo cheese ${ }^{1}$

\begin{tabular}{ll}
\hline Attribute & Definition \\
\hline Flavor & The fundamental taste sensation of which sodium chloride is typical \\
Salty & The fundamental taste sensation of which lactic and citric acids are typical \\
Acidic & The fundamental taste sensation of which caffeine and quinine are typical \\
Bitter & The fundamental taste sensation of which sucrose is typical \\
Sweet & The taste associated with molds, usually earthy, dirty, stale, musty, and slightly sour \\
Moldy & The taste associated with sour milk and oxidized fats, having the rank of an unpleasant \\
Rancid & aroma or taste characteristic of oils and fats when no longer fresh \\
Piquant & The taste associated with an irritating or aggressive sensation perceived in the mouth or in the throat \\
Grass & Sensory attribute perceptible by the olfactory organ via the back of the nose as freshly cut grass \\
Fermented & The taste associated with a very ripe cheese \\
Strength & The overall intensity of aroma and flavor; the degree of mildness and maturity \\
Appearance & The color of cheese, ranging from pale yellow to orange, with the palest of yellow representing the start of the scale \\
Color & The evenness of color shading within the cheese sample, with the most uniformly colored \\
Mottling & cheese being free of mottling, marbling, or any other deficiencies in color \\
& The extent to which the surface of the cheese is shiny, glossy, moist, or \\
Shiny & sweaty looking, as opposed to looking matte or dull \\
Open & The extent to which the interior of the cheese (that is, the cut surface) is open; this \\
encompasses cracks, pinholes, irregular-shaped holes, and any other openings \\
Texture & The extent to which the cheese has a moist or wet texture around the palate during mastication \\
Moist & The extent to which the cheese returns to its initial form after biting (assessed during the first 2 to 3 chews) \\
Rubbery & The extent to which granular structures are formed as the sample breaks down (perceived in the second half of chewing) \\
Grainy & The extent to which the cheese coats the palate and teeth during mastication \\
Mouth-coating &
\end{tabular}

${ }^{1}$ Adapted, with permission, from Murray and Delahunty (2000).

\section{RESULTS AND DISCUSSION}

Consumer sensory analysis was performed on Monti Dauni Meridionali Caciocavallo cheese produced from 6 dairy factories located in the geographical area of southern Italy known as Monti Dauni Meridionali. In a previous note, Albenzio et al. (2010) surveyed the traditional protocols used in this geographical area to produce a popular dairy product in the local market. These authors reported the use of both raw and thermized milk, natural or commercial starter, liquid or paste rennet, manual or mechanical stretching of the curd, and finally, different concentrations of the brine for salting, indicating that the nutritional quality and maturation process of the cheeses were influenced by milk quality and characteristic phases of the artisanal protocols used for cheese making.

The sensory attributes of cheese were categorized as appearance, flavor, and texture. Appearance attributes of Caciocavallo cheese from the 6 dairy factories involved in the trial are reported in Table 3 . The highest scores for shiny were assigned to cheeses B, C, and E, and the lowest was assigned to cheese $\mathrm{F}$. The interior of the cheese exhibited small pinholes, as also reported for Caciocavallo Pugliese cheese (Gobbetti et al., 2002). The open attribute encompassed cracks, pinholes, and irregular-shaped holes and received the lowest scores in cheeses B, C, and E. Cheeses were not different in terms of color uniformity, which showed values greater than 6; color intensity was the lowest in cheeses B, C, and $\mathrm{E}$ and the highest in cheeses A, D, and F. Overall, Caciocavallo cheeses were judged quite evenly colored and free of marbling or other deficiencies in color.

Flavor attributes of Caciocavallo cheese produced from the 6 dairy factories are reported in Figure 1. No differences among cheeses were found for the sweet $(3.36 \pm 0.38$; mean $\pm \mathrm{SE})$, moldy $(1.98 \pm 0.38)$, acid $(3.87 \pm 0.38)$, grass $(2.74 \pm 0.35)$, bitter $(3.56 \pm 0.40)$, and rancid attributes $(2.02 \pm 0.35)$, whereas the salty and piquant attributes were higher in cheeses $\mathrm{F}$ and A. The overall intensity of aroma and flavor, described by consumers as strength, scored the lowest values in cheeses B, C, D, and E $(5.56,5.54,5.98$, and $5.74 \pm$ 0.25 , respectively), intermediate in cheese A (6.75 \pm $0.25)$, and the highest in cheese $\mathrm{F}(7.83 \pm 0.25 ; P<$ $0.001)$.

The extensive lipolysis in cheeses $\mathrm{A}$ and $\mathrm{F}$, in terms of the highest content of FFA (Table 1), could have been responsible for the intense and piquant flavor in the aforementioned cheeses. The better nutritional quality of the processed milk, in terms of fat, protein, and casein in factories $\mathrm{A}$ and $\mathrm{F}$, together with the use of raw milk in the production of cheese $\mathrm{F}$ and calf rennet paste in cheese A, played an important role during cheese ripening, as reported by Albenzio et al. (2010). Pinho et al. (2003) reported that excessive lipolysis could result in the presence of off-flavors because high concentrations of volatile FFA influence cheese flavor, either 
Table 3. Appearance and texture attributes $( \pm \mathrm{SEM})$ of Caciocavallo cheese produced by 6 factories located in the Monti Dauni Meridionali area

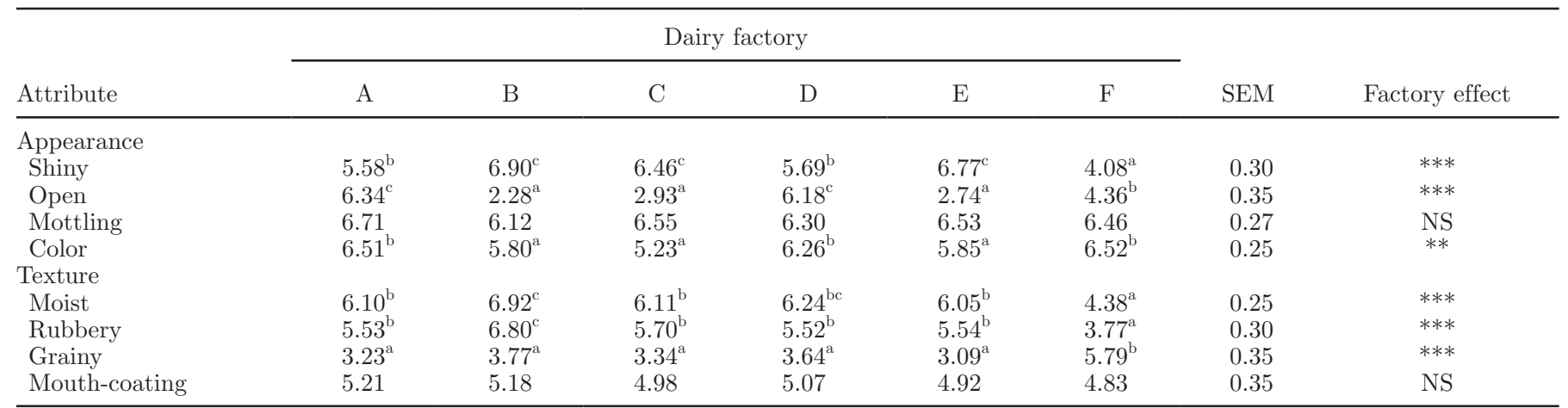

${ }^{\mathrm{a}-\mathrm{c}}$ Means within a row with different superscripts differ $(P<0.05)$.

${ }^{* *} P<0.01 ; * * * P<0.001$.

directly or as precursors of other compounds. However, in this study, greater lipolysis was not associated with the perception of a bitter flavor by consumers.

Positive correlations were found between strength and soluble nitrogen at $\mathrm{pH} 4.6(\mathrm{r}=0.77 ; P<0.01)$, lower molecular weight peptides $(\mathrm{r}=0.57 ; P<0.05)$, and total FFA $(\mathrm{r}=0.98 ; P<0.001)$, and between piquant and total FFA $(\mathrm{r}=0.92 ; P<0.001)$, butyric acid $(\mathrm{r}=0.75 ; P<0.001)$, and caproic acid $(\mathrm{r}=0.89$; $P<0.001)$. In addition, in ovine cheese, short-chain FFA are related to the strength of cheese, with higher odor and flavor intensity scores associated with higher amounts of short-chain FA (C4:0 to C10:0) and FFA (Virto et al., 2003). One of the main off-flavors perceived by the consumers was associated with bitterness, which was correlated with the concentration of peptides and soluble nitrogen at pH 4.6 (Molimard et al., 1997). In Monti Dauni Meridionali Caciocavallo cheese, bitterness scored less than 4.5, and no correlations were detected between this parameter and ripening indexes as the soluble nitrogen ripening fraction, lower molecular weight peptides, and FFA.

Textural attributes of Caciocavallo cheese from 6 dairy factories are reported in Table 3. Pasta filata

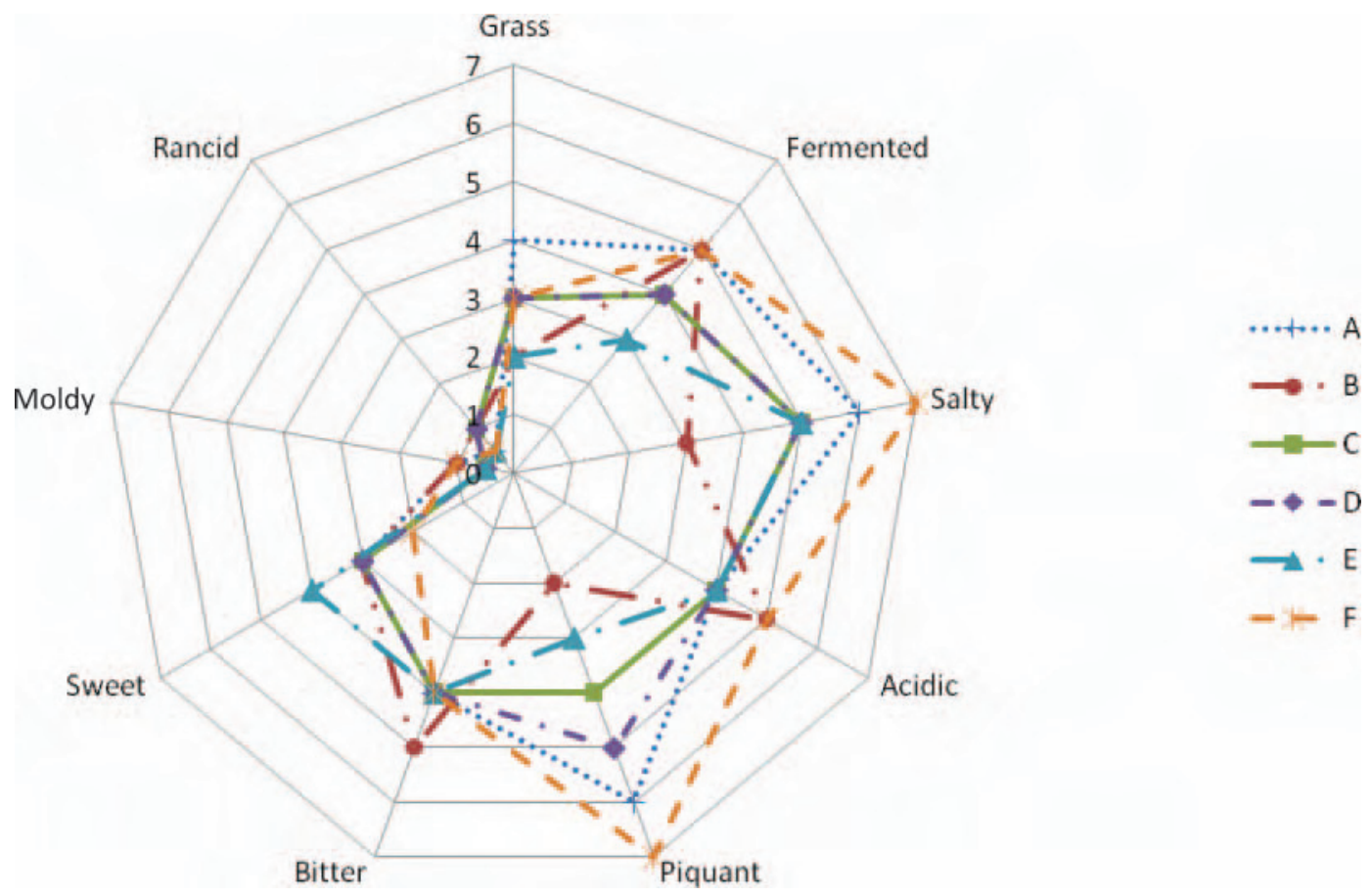

Figure 1. Flavor attributes of Caciocavallo cheese produced by 6 factories (A, B, C, D, E, F) located in the Monti Dauni Meridionali area. Color version available in the online PDF. 
cheeses are characterized by the perception of a fibrous structure during cheese consumption (Everett and Auty, 2008), especially for short-time ripened products, such as Mozzarella cheese. In this study, Caciocavallo cheese underwent an extensive proteolytic and lipolytic process over 6 mo of ripening, which was responsible for modifications of the cheese texture. Consumers assigned quite a high rubbery score for all cheeses except cheese $\mathrm{F}$ because farm $\mathrm{F}$ had the lowest percentage of salt in the brine used for cheese salting (Albenzio et al., 2010). In fact, Everett et al. (2004) reported that salting of the curd enhances protein swelling and hydration, which results in bulk water being absorbed by the casein phase, and casein hydration is enhanced by high levels of sodium chloride. Moreover, consumers perceived a more granular structure during the second half of chewing of Caciocavallo cheese F, as evidenced by the highest value for the grainy attribute.

Principal components analysis of sensory attributes of the Monti Dauni Meridionali Caciocavallo cheese evaluated by panelists is reported in Figure 2. The PCA analysis applied to sensory attributes accounted for
$64.61 \%$ of the total variance. Strength, salty, piquant, and fermented were the main factors explained by the first principal component, whereas moisture, shiny, rubbery, color, open, and grainy were the dominating factors along the second principal component. The score plot showed that cheeses $\mathrm{F}$ and $\mathrm{A}$ were located in a well-defined zone of the plot with cheese displaying higher levels of strength, piquant, and salty attributes. It is worth noting that cheeses $\mathrm{B}, \mathrm{C}, \mathrm{D}, \mathrm{E}$, and $\mathrm{F}$ were located in the same part of the plot within the sex of the panelists. In contrast, the score plot showed how cheese A, evaluated by female panelists, lay in a zone where the salty, piquant, fermented, and strength attributes were predominant when compared with those of the same cheese tested by male panelists. Cheese F was characterized by both female and male panelists by a higher overall intensity of aroma and flavor and a grainy texture. Cheeses $\mathrm{A}$ and $\mathrm{F}$ received the highest number of preferences, with $40 \%$ preferring cheese $\mathrm{A}$ and $38 \%$ preferring cheese $\mathrm{F}$, whereas $9 \%$ preferred cheese $\mathrm{E}, 8 \%$ preferred cheese $\mathrm{D}$, and $7 \%$ preferred both cheeses $\mathrm{B}$ and $\mathrm{C}$. The preference test within sex indi-

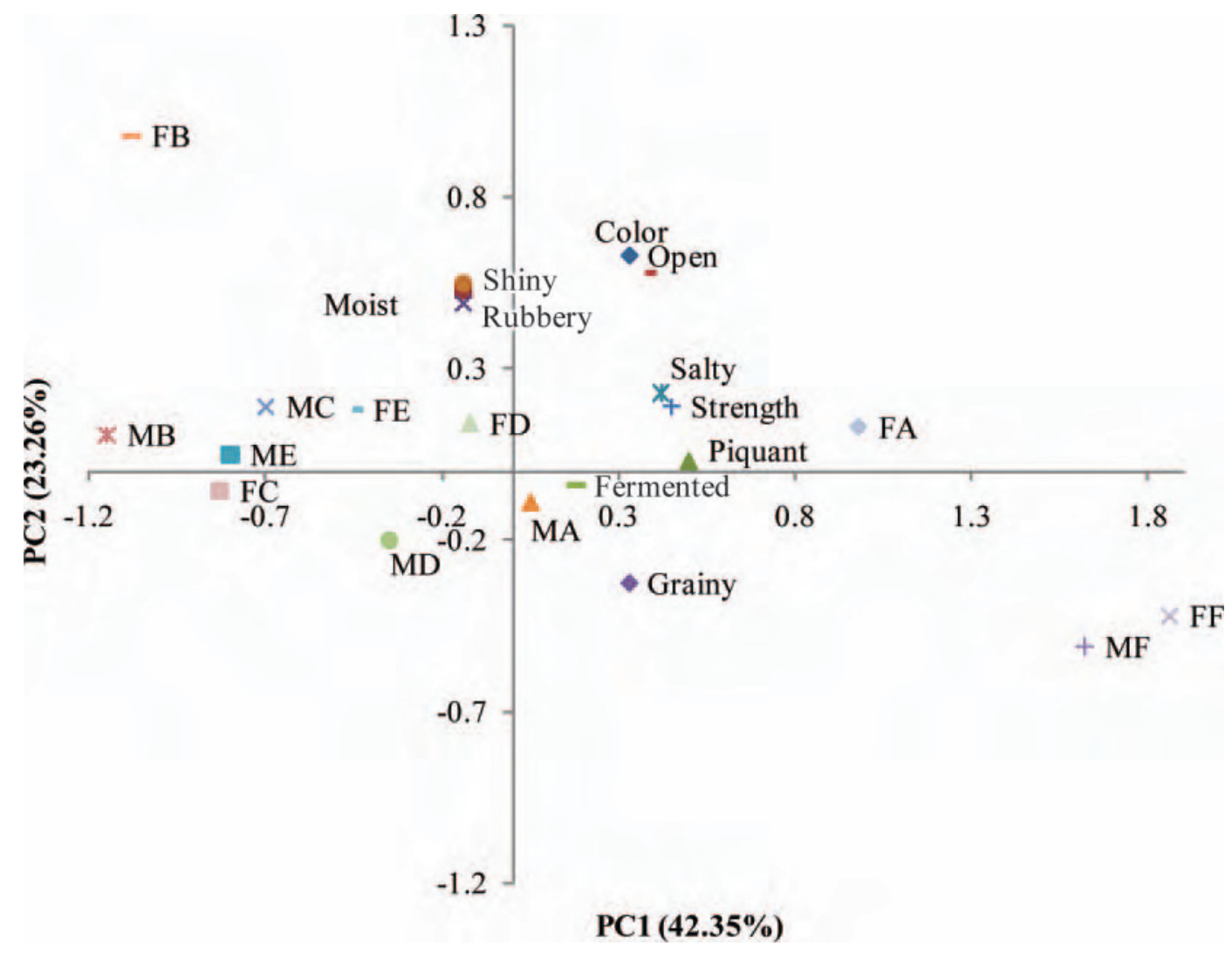

Figure 2. Principal components analysis of sensory parameters of Monti Dauni Meridionali Caciocavallo cheese according to sex of the panelist $(\mathrm{F}, \mathrm{M})$ and factory $(\mathrm{A}, \mathrm{B}, \mathrm{C}, \mathrm{D}, \mathrm{E}, \mathrm{F}) . \mathrm{FA}=$ female, factory $\mathrm{A} ; \mathrm{FB}=$ female, factory $\mathrm{B}$; FC = female, factory C; FD = female, factory $\mathrm{D}$; $\mathrm{FE}=$ female, factory $\mathrm{E} ; \mathrm{FF}=$ female, factory $\mathrm{F} ; \mathrm{MA}=$ male, factory $\mathrm{A} ; \mathrm{MB}=$ male, factory $\mathrm{B} ; \mathrm{MC}=$ male, factory $\mathrm{C} ; \mathrm{MD}=$ male, factory $\mathrm{D} ; \mathrm{ME}=$ male, factory $\mathrm{E} ; \mathrm{MF}=$ male, factory $\mathrm{F}$. Color version available in the online PDF. 
cated that $75 \%$ of females preferred Caciocavallo cheese A, whereas an equal number of males and females expressed a preference for cheese $\mathrm{F}$.

\section{CONCLUSIONS}

The positive correlation between sensory attributes and cheese-ripening indexes indicated that consumers' preference was oriented toward cheeses with an overall higher degree of maturity, as determined by the use of raw milk, the adjunct of calf rennet as coagulant, and a moderate concentration of brine for cheese salting. A sensory evaluation of Monti Dauni Meridionali Caciocavallo cheese is useful for highlighting the principal attributes able to influence consumers' liking and preference. The results may help dairy operators ameliorate specific phases of Caciocavallo cheese production that play a crucial role in defining cheese maturation and sensory characteristics.

\section{ACKNOWLEDGMENTS}

The authors thank Concetta Perilli and Donatella Esterina Russo (both from Department PrIME, University of Foggia, Italy) for expert technical assistance.

\section{REFERENCES}

Albenzio, M., A. Santillo, D. E. Russo, M. Caroprese, R. Marino, and A. Sevi. 2010. Influence of milk quality and production protocol on proteolysis and lipolysis in Monti Dauni Meridionali Caciocavallo cheese. J. Dairy Res. 77:385-391.

Everett, D. W., and M. A. E. Auty. 2008. Cheese structure and current methods of analysis. Int. Dairy J. 18:759-773.
Everett, D. W., M. K. Rowney, M. W. Hickey, and P. Roupas. 2004 Salt-induced structural changes in Mozzarella cheese and the impact upon free oil formation in ripening cheese. Lait 84:539-549.

Gobbetti, M., M. Morea, F. Baruzzi, M. R. Corbo, A. Matarante, T. Considine, R. Di Cagno, T. Guinee, and P. F. Fox. 2002. Microbiological, compositional, biochemical and textural characterisation of Caciocavallo Pugliese cheese during ripening. Int. Dairy J. $12: 511-523$.

Kupiec, B., and B. Revell. 1998. Specialty and artisanal cheese today: The product and the consumer. Br. Food J. 100:236-243.

Kuznesof, S.. A. Tregear, and A. Moxey. 1997. Regional foods: A consumer perspective. Br. Food J. 99:199-206.

Molimard, P., I. Lesschaeve, S. Issanchou, M. Brousse, and H. E. Spinnler. 1997. Effect of the association of surface on the sensory properties of mould-ripened cheese. Lait 77:181-187.

Muir, D. D., and E. A. Hunter. 1992. Sensory evaluation of Cheddar cheese: Order of tasting and carryover effects. Food Qual. Prefer. $3: 141-145$.

Murray, J. M., and C. M. Delahunty. 2000. Mapping consumer preference for the sensory and packaging attributes of Cheddar cheese. Food Qual. Prefer. 11:419-435.

Ophuis, P. A. M., and H. C. M. Van Trijp. 1995. Perceived quality: A market driven and consumer oriented approach. Food Qual. Prefer. 6:177-183.

Pinho, O., I. M. P. L. V. O. Ferreira, and M. A. Ferriera. 2003. Quantification of short-chain free fatty acids in "Terrincho" ewe cheese: Intravarietal comparison. J. Dairy Sci. 86:3102-3109.

Piraino, P., T. Zotta, A. Ricciardi, and E. Parente. 2005. Discrimination of commercial Caciocavallo cheeses on the basis of the diversity of lactic microflora and primary proteolysis. Int. Dairy J. 15:1138-1149.

SAS Institute. 2011. SAS User's Guide: Statistics. Version 9.2 ed. SAS Inst. Inc., Cary, NC.

Shapiro, S. S., and M. Wilk. 1965. An analysis of variance test for normality. Biometrika 52:591-601.

Vernile, A., G. Spano, A. Lecce, D. Tarantino, L. Beneduce, and S. Massa. 2006. Microbiological and chemical characteristics of "Monti Dauni Meridionali" Caciocavallo cheese. Adv. Food Sci. 28:2-6.

Virto, M., F. Chavarri, M. A. Bustamante, M. Barron Aramburu, M. S. Vicente, F. J. Perez-Elortando, M. Albisu, and M. de Renobales. 2003. Lamb rennet paste in ovine cheese manufacture. Lipolysis and flavor. Int. Dairy J. 13:391-399. 